\title{
Screening fitness to drive by occupational therapists in Gauteng Public Healthcare - an Action Learning Action Research outcome
}

\author{
Hester van Biljon, B Occ Ther (UFS), M Occ Ther (UFS), PhD (Wits) https://orcid.org/0000-0003-4433-6457 \\ Private practitioner at Work-link Vocational Rehabilitation practice \\ Daleen Casteleijn, B Occ Ther (Pret), B Occ Ther (Hons)(Medunsa), Dip Voc Rehab (Pret), DHETP (Pret), M Occ \\ Ther (Pret), PhD (Pret) https://orcid.org/0000-0002-06 I I-8662 \\ Associate Professor, University of the Witwatersrand, Faculty of Health Sciences, School of Therapeutic Sciences, Occupational \\ Therapy Department
}

Simon Rabothata, B Occ Ther UL (Medunsa), Post Grad Dip Voc Rehab UP https://orcid.org/0000-000I-9102-9893 Assistant Director, Therapeutic \& Medical Support Services, Gauteng Health Department, Johannesburg

Sanetta HJ du Toit, B Occ Ther (UFS), M Occ Ther (UFS), MSc Occ Ther (University of Exeter, UK), PhD (UFS) https://orcid.org/0000-0003-1348-63 I3

Affiliated lecturer, University of the Free State, Department of Occupational Therapy. Lecturer, University of Sydney, Faculty of Health Sciences, Discipline of Occupational Therapy

Introduction: In South Africa, public healthcare users equate the ability to drive a motor vehicle to employability and access to essential services. When injury or illness threatens the ability to drive, the multi-professional medical team usually refer the problem to the occupational therapist who will make decisions about patients' fitness to drive a motor vehicle.

Method: Over the course of five years, a collaborative task team applied multiple Action Learning Action Research (ALAR) cycles to address the problem. Qualitative data collected included field notes, reflective journaling, meeting minutes and a survey.

Results: ALAR cycles resulted in a user manual and tool to screen driver fitness for occupational therapists. A follow-up survey indicated that despite a low user ratio, clinicians were of the opinion that the screening tool was user-friendly and contextually relevant to their practices.

Conclusion: ALAR was effective in addressing a practice problem and empowering clinicians to develop a structured approach to screen fitness to drive in patients accessing public healthcare. Screening, as a first step within the field of driving rehabilitation, is now available in Gauteng public healthcare.

Key words: Driving rehabilitation, driving screening, public healthcare, action research action learning

\section{INTRODUCTION}

Driving is categorised as an instrumental activity of daily living $(I A D L)^{\prime}$. In South Africa, the ability to drive a motor vehicle is a venerated skill and popularly considered an entry to the labour market. Public healthcare serves $84 \%$ of South African healthcare users ${ }^{2}$, where heavy patient-loads at overburdened, understaffed and illequipped facilities often result in compromised healthcare quality ${ }^{3}$. At the time of this research there were no driving rehabilitation services in Gauteng public healthcare, despite it being one of South Africa's best healthcare resourced provinces ${ }^{4}$. Individual therapists working as driving experts and several private occupational therapy practices offered driving rehabilitation but these services were fiscally and physically inaccessible to public healthcare users.

The June 2014 National Household Travel Survey ${ }^{5}$ showed 12,6 million people resided in Gauteng and $40 \%$ of the older than 18 years population had drivers' licences. Drivers that use public healthcare are frequently employed in the formal or informal public transport industry. These drivers are often sole breadwinners for extended families, making them desperate to return to driving as it safeguards their income and ensures access to essential services, such as schools and clinics, and maintains their social status for themselves and their families.
Occupational therapy as a profession has an acknowledged role within the field of driving rehabilitation ${ }^{6}$. Internationally there are occupational therapy associations that provide clear driving rehabilitation practice guidelines ${ }^{7}$. In South Africa guidance to occupational therapists and/or position statements within the field of driving rehabilitation are still only developing and calls for investigation and clarity ${ }^{8}$.

In South African public healthcare, occupational therapists face challenges that are typically experienced in a developing economy? In addition, they witness a high staff turnover and the bulk of clinical work is delivered by newly graduate community service occupational therapists with limited clinical experience ${ }^{10}$. The Gauteng Vocational Rehabilitation Task Team (VRTT) is an interest group of occupational therapists concerned with vocational rehabilitation services in Gauteng public healthcare. They took note of the problem that clinicians needed guidance on the nature and extent of addressing the driving ability of patients after injury or illness. Positioning driving rehabilitation, with its associated complexity, high level of responsibility and possible legal repercussions, within an already burdened public healthcare sector was problematic. In addition it would require commitment to a multi-level collabora- 
tive process to ensure guidance by experts and buy-in on service delivery level" .

The aim of this article was to present an Action Learning Action Research (ALAR) process that resulted in the development of a Screening Fitness to Drive tool and user manual.

\section{LITERATURE REVIEW}

Driving can be described as an act of safely operating a motor vehicle to a goal-directed destination ${ }^{12}$. Inability to drive could have severe repercussions for drivers, passengers and the environment within which the driving takes place ${ }^{6}$. When considering fitness to drive, the synthesis between functional ability, skill, experience and behaviour is a complex one ${ }^{13}$. This gets more complex if impairment, disability, medication, vehicle adaptations, assistive devices and compensatory aids are added to the mix. The latter is the domain of driving rehabilitation.

Driving rehabilitation is an intervention to redress impairment related to the driving task and to facilitate fitness to drive ${ }^{14}$. The field comprises a multi-disciplinary approach ${ }^{15}$ of screening, assessment, intervention, accommodation, adaptations and modification to ensure safe driving. Screening tools are used to identify persons at risk of failing on-road assessments ${ }^{16}$. Driving evaluation consists of a clinical, off-road assessment followed by an on-road assessment ${ }^{17}$. Driving efficiency is improved with on-road driving rehabilitation ${ }^{18}$ and a variety of interventions, such as computer-based driving simulator training, off-road skill-specific training and off-road education programmes $^{19}$. Accommodation, adaptation and modification of motor vehicles are also prevalent interventions in the field ${ }^{20}$. Driver screening is thus the start of a multi-facetted service available to those whose driving ability is at risk ${ }^{21}$.

Occupational therapists' knowledge of pathology/injury/illness, combined with a knowledge of activity requirement, positions them to bridge the gap between healthcare institutions and the public sphere ${ }^{22}$ where driving takes place. Davis et $\mathrm{al}^{23}$ states that the skills, knowledge base, and scope of practice of occupational therapy, enhanced by advanced education in driving rehabilitation, places the profession in the vanguard of driving rehabilitation. They further state that driving rehabilitation warrants attention in all areas of occupational therapy practice. Occupational therapists are globally active in the field of driving rehabilitation ${ }^{6}$. They investigate and make complex decisions regarding fitness to drive ${ }^{24}$ and are involved in enablement of people with disabilities to drive motor vehicles $^{19}$. There is also evidence to show that occupational therapists investigate the reliability of the tests ${ }^{25}$ and assessments ${ }^{26}$ that they commonly use in this field.

In South Africa, scientific evidence of the profession's involvement in driving rehabilitation is sparse. There is however prolific evidence of this in grey literature, such as in the official newsletter of the Occupational Therapy Association of South Africa ${ }^{27}$, other professional magazines ${ }^{28}$ and newspapers. A research study that explores the lived experiences of South African spinal cord injured drivers ${ }^{8}$ identified the lack of rehabilitation professionals' involvement in driving rehabilitation research. It calls for scientific evidence from South African occupational therapists in the field of driving rehabilitation.

Driving a motor vehicle in public, demands regulation ${ }^{29}$. The demand intensifies when people with disabilities, and the elderly, drive motor vehicles, as ethical issues related to the protection and rights of vulnerable persons, join the fray. South African occupational therapists need an awareness of the potential consequences of their decisions and interventions in driving rehabilitation. Alternatively, they should be aware of the repercussion when they avoid making decisions or refuse to offer intervention. A sound knowledge of South African legislation and national strategies, policies and protocols that have an impact on driving a motor vehicle are necessary. As driving is often linked with employment, a working knowledge of labour legislation is also needed. In addition, therapists have to continue to comply with their professional codes of conducts and their patients' rights.
It is within such complex and multifarious realities that Action Research was found to be an effective methodology ${ }^{30}$. In addition the methodology allows practitioners to address practice problems while generating contextually relevant knowledge ${ }^{31}$.

\section{METHOD}

\section{Study design}

This study was guided by the epistemology of action learning and action research (ALAR) during the five years of inquiry described in this article. The typical action research cycles ${ }^{32}$ of observe, plan, act and reflect was seen as cycles within cycles as it occurred on an individual and group basis. The ALAR design allowed learning ${ }^{33}$, emancipation and transformation ${ }^{34}$ to take place, as participants were included as fellow researchers ${ }^{35}$ generating knowledge within their clinical practices to which they and their patients could relate ${ }^{36}$.

\section{Population and Sampling Procedure}

In action research, the term stakeholders ${ }^{37}$ is used to describe populations who would be affected by or are able to affect practical change. In this study, stakeholders can be seen as insiders, research participants within public healthcare, or outsiders, (research participants who were not affiliated with public healthcare). There were five stakeholder groups.

The first was a collaborative research group that consisted of an insider interest group, the Vocational Rehabilitation Task Team (VRTT), and an outsider, a PhD candidate (the first author). The VRTT was a group of occupational therapists with an interest in vocational rehabilitation, working at various levels in Gauteng's public healthcare sector. Their positions ranged from Head Office management to Community Service occupational therapists. Group membership changed continuously, fluctuating between five and I2. The PhD candidate, an outsider, was an honorary member of the VRTT. Her PhD, titled Transforming Vocational Rehabilitation in Occupational Therapy Departments in Gauteng's Public Healthcare through Action Research Action Learning, concurred with the VRTT vision.

For the Screening Fitness to Drive study, the collaborative research team incorporated additional insiders groups. The second stakeholder group was an insider group of occupational therapists who attended the 2014 Vocational Rehabilitation Orientation Workshop. They were predominantly community service occupational therapists who had graduated the previous year and needed to do a year of community service in a public healthcare institute of their choice ${ }^{38}$. These attendees were invited to become part of the research collaboration and 38 of them volunteered to take part.

The 2015 research cycles were the third stakeholder insider group, and consisted of I0 VRTT members and six clinical occupational therapists who worked together in clinical public healthcare settings.

The fourth was an outsider group of nine experts in the field of driving rehabilitation; they were enlisted as critical friends ${ }^{39}$ in the study for their opinions and comments. The selection criteria for this group were occupational therapists with previous or current experience in South Africa's public healthcare and with more than five years of experience in the field of driving rehabilitation.

The fifth stakeholder group were insider occupational therapists who took part in a survey that was sent to 37 public healthcare institutions. Table I on page 6 shows how stakeholders fit into the data collection process and consequent results.

\section{DATA COLLECTION}

The data gathering process for this inquiry took place over five years, from September 2013 to April 2017, in the form of annual action research cycles. The VRTT used the first meeting of a year to plan. Throughout the year, planned actions took place, data was analysed, processed and reported back at each meeting. The last meeting of the year was used to critically reflect on the year's actions. Figure I on page 6 shows the process of the five year study. 
Table I: Stakeholders, data collection process and results

\begin{tabular}{|c|c|c|c|}
\hline Timeline & Stakeholders & Research process and Data Collection Tools & Results \\
\hline $\begin{array}{l}\text { Observation } \\
\text { and Planning } \\
2013\end{array}$ & $\begin{array}{l}\text { VRTT }(N=5) \\
\text { Critical Friends } \\
(N=9 n=3)\end{array}$ & $\begin{array}{l}\text { Process: A practice problem identified and grounding premises } \\
\text { discussed. Action research cycles were used to develop a draft } \\
\text { Screening Ability to Drive user manual. Critical friends provided } \\
\text { input. } \\
\text { Tools: Field notes, reflective journaling, VRTT meeting minutes }\end{array}$ & $\begin{array}{l}\text { - Grounding premises (See Table III). } \\
\text { - Draft Screening Ability to Drive tool and } \\
\text { user manual. }\end{array}$ \\
\hline Cycle I 2014 & $\begin{array}{l}\text { Orientation } \\
\text { workshop } \\
\text { attendees } \\
(\mathrm{N}=38, \mathrm{n}=2) \\
\text { VRTT mentors } \\
\quad(\mathrm{N}=9)\end{array}$ & $\begin{array}{l}\text { Process: Occupational therapists attending the annual Voca- } \\
\text { tional Rehabilitation Orientation Workshop were introduced } \\
\text { to the screening tool and invited to take part in the research. } \\
\text { Volunteering participants were allocated a mentor. Participation } \\
\text { required tool use, keeping reflective journals and communicat- } \\
\text { ing suggestions for tool improvement. } \\
\text { Tools: Field notes, reflective journaling, VRTT meeting minutes. }\end{array}$ & $\begin{array}{l}\text { - Two of the } 38 \text { workshop attendees } \\
\text { who signed consent forms complied. } \\
\text { - VRTT applied critical reflection to } \\
\text { adapt the research process. }\end{array}$ \\
\hline Cycle 22015 & $\begin{array}{l}\text { VRTT } \\
(\mathrm{N}=10)(\mathrm{n}=8) \\
\text { Clinical OT's } \\
\text { and VRTT } \\
\text { mentors } \\
(\mathrm{N}=16)\end{array}$ & $\begin{array}{l}\text { Process: VRTT members undertake to ask colleagues work- } \\
\text { ing with them to join the research team. Co-opted colleagues } \\
\text { sign consent forms, briefed on tool use and mentored by VRTT } \\
\text { members experienced in using the tool in their own clinical } \\
\text { practice. } \\
\text { Tools: Field notes, reflective journaling, VRTT meeting minutes. }\end{array}$ & $\begin{array}{l}\text { - Sixteen clinical OT's and VRTT } \\
\text { members used the tool and provided } \\
\text { feedback. } \\
\text { - Tool is improved and finalised. } \\
\text { - Clinical guide is developed (See Figure } \\
\text { Two) }\end{array}$ \\
\hline $\begin{array}{l}\text { Dissemination } \\
2016\end{array}$ & $\begin{array}{c}\text { VRTT } \\
(\mathrm{N}=12) \\
\text { OTASA } \\
\text { congress pre- } \\
\text { senters }(\mathrm{N}=2)\end{array}$ & $\begin{array}{l}\text { Process: Dissemination of the screening tool through public and } \\
\text { private healthcare forums and nationally at the Occupational } \\
\text { Therapy Association of South Africa Congress. All users were } \\
\text { encouraged to provide feedback. } \\
\text { Tools: Field notes, reflective journaling, VRTT meeting minutes. }\end{array}$ & $\begin{array}{l}\text { - Continued improvement and develop- } \\
\text { ment of the tool. } \\
\text { - Dissemination showed an increased } \\
\text { interest and tool distribution. }\end{array}$ \\
\hline Survey 2017 & $\begin{array}{l}\text { Orientation } \\
\text { workshop } \\
\text { attendees } \\
(\mathrm{N}=32) \\
\text { VRTT }(\mathrm{N}=10) \\
\quad \text { Survey } \\
(\mathrm{N}=37 \mathrm{n}=12)\end{array}$ & $\begin{array}{l}\text { Process: Presentation at annual Vocational Rehabilitation Orien- } \\
\text { tation Workshop continues with requests for feedback. } \\
\text { A survey completed to explore the use of the screening tool in } \\
\text { all Gauteng's healthcare institutions. } \\
\text { Tools: Field notes, reflective journaling, VRTT meeting minutes, } \\
\text { Survey. }\end{array}$ & $\begin{array}{l}\text { - Improvement of the tool continued. } \\
\text { - A } 32 \% \text { survey response rate indicated } \\
\text { agreement on the contextual relevance } \\
\text { of the tool and its application value. } \\
-41 \% \text { of participants used the screening } \\
\text { tool twice a year. } \\
\text { - Findings compiled for publication. }\end{array}$ \\
\hline
\end{tabular}

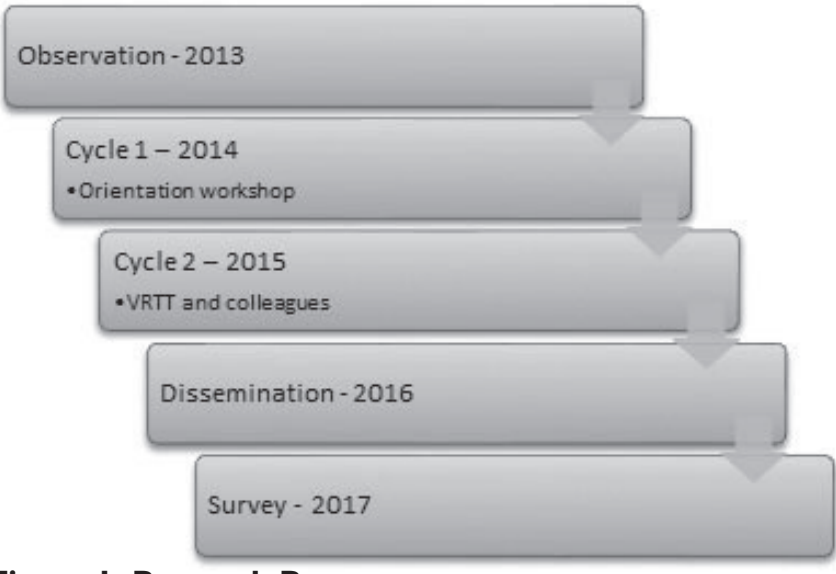

Figure I: Research Process

When the PhD candidate joined the VRTT in 20I3, one of the first practice problems tabled was the question of what should occupational therapists in public health be doing regarding driving rehabilitation. The problem was defined and a decision was made to address it with ALAR. Observation and planning to address the problem ensued.

The collaborative research team commissioned the PhD candidate to draw up a draft screening of fitness to drive user manual; she did so using individual action research cycles ${ }^{40}$. The course-work of a driving rehabilitation workshop and a driver-screening process, already in use by the candidate's private practice, was employed to develop the draft. This was sent to critical friends who were experts in the field of driving rehabilitation and their feedback and suggestions were worked into the draft. The draft screening fitness to drive user manual was presented to the VRTT at the last 2013 meeting. Collectively a decision was made to use it in public healthcare, putting it through multiple cycles of planning, action and reflection.

The VRTT decided to use the 2014 Vocational Rehabilitation Orientation Workshop to launch the first ALAR cycle of the driverscreening user manual. Attendees of this workshop were invited to use the Screening Fitness to Drive tool with their patients and provide feedback in the form of critical reflections. At the orientation workshop, the dynamics of ALAR cycles were explained, the draft user manual was presented and a screening demonstrated. Attendees who volunteered to participate in the research signed consent forms, were assigned a mentor (one of the VRTT members) and followed up on a regular basis. Feedback of progress was given at each VRTT meeting and this continued until the end of the year. Results informed the VRTT that the plan was not working. Therapists were not using the tool and very little feedback was received. The decision was made to attempt a new approach in 2015.

At the first meeting, in 2015, the VRTT decided that all VRTT members were to use the Screening Fitness to Drive tool with their patients and invited colleagues working with them to join the second ALAR cycle. They would teach colleagues to use the screening tool, mentor them and capture critical reflections and suggestions to feedback at the VRTT meetings. This feedback was used to improve the tool and user manual. By the end of the year, the tool and user manual were improved and the decision was taken to finalise them. The $\mathrm{PhD}$ candidate did this, again sending them to critical friends whose feedback was incorporated. It was sent for language editing and compiled into an easy to use, bound, hard copy manual and an electronic format.

In 2016 , the user manual was disseminated through official public healthcare channels to all clinical occupational therapists working in Gauteng. The annual presentation and practical demonstration at the Vocational Rehabilitation Orientation workshop continued, introducing it to occupational therapists entering Gauteng public healthcare. All critical friends received a copy, and it was shared 


\begin{tabular}{|c|c|c|}
\hline Composition & Distribution & Results \\
\hline $\begin{array}{l}\text { The survey was to be filled by the Head of Depart- } \\
\text { ment, or a designated clinician, from each Institu- } \\
\text { tion. } \\
\text { The questions were formulated to address the aim } \\
\text { of the survey. } \\
\text { The aim was: To investigate the value and use of the } \\
\text { Driver Screening Tool in Gauteng Health's occupa- } \\
\text { tional therapy services. }\end{array}$ & $\begin{array}{l}\text { The survey was sent to all institutions with } \\
\text { occupational therapy services, through the } \\
\text { official Gauteng Health Head Office email. } \\
\text { A five day return time was given and the } \\
\text { survey was attached as an addendum. }\end{array}$ & $\begin{array}{l}41 \% \text { of responding facilities used the } \\
\text { Driver Screening Tool. } \\
\text { Respondents who used the tool indicated } \\
\text { they did so only once or twice a year. }\end{array}$ \\
\hline $\begin{array}{l}\text { There were three sections: } \\
\text { I. Has the Driver Screening Tool been used in your } \\
\text { Department? } \\
\text { Yes/No If Yes how often? If No why not? } \\
\text { 2. Does the Driver Screening Tool add value to the } \\
\text { services you offer your patients? } \\
\text { Yes/No Please elaborate } \\
\text { 3. Are there any comments, recommendations or } \\
\text { suggestions regarding the Driver Screening Tool? }\end{array}$ & $\begin{array}{l}\text { The Survey was sent to: } \\
4 \text { Quaternary Hospitals } \\
3 \text { Tertiary Hospitals } \\
9 \text { Regional Hospitals } \\
\text { I0 District Hospitals } \\
6 \text { Specialised Hospitals } \\
5 \text { Community health Centres } \\
\text { Total of } 37 \text { institutions }\end{array}$ & $\begin{array}{l}91 \% \text { of respondents who had used the } \\
\text { tool were positive. } \\
8 \% \text { of respondents included negative } \\
\text { feedback about the tool. }\end{array}$ \\
\hline $\begin{array}{l}\text { The survey was in the form of a Word Document } \\
\text { that could be filled in electronically and it was anal- } \\
\text { ysed by hand. }\end{array}$ & $\begin{array}{l}\text { Ist round was sent on } 5 \text { April } 2017 \text { to all } \\
\text { institutions: } \\
N=37 \quad n=5 \text {. } \\
\text { 2nd round was sent on } 18 \text { April } 2017 \text { to } \\
\text { non-responsive institutions: } \\
N=32 \quad n=7 \text {. } \\
\text { Total response of } 12 / 37 \text { gives a } 32 \% \text { re- } \\
\text { sponse rate. }\end{array}$ & $\begin{array}{l}\text { Thematic analysis of the positive re- } \\
\text { sponses showed two themes: } \\
\text { - The tool was user friendly. } \\
\text { - The tool was contextually relevant to } \\
\text { their practices. } \\
\text { Thematic analysis of the negative } \\
\text { responses showed an ethical veracity } \\
\text { concern. }\end{array}$ \\
\hline
\end{tabular}

with private practitioners, academic institutions and public healthcare managers from other provinces who expressed interest. At the National Occupational Therapy Association of South Africa Congress, 2016, an oral presentation was given ${ }^{41}$.

In 2017, the VRTT launched a survey to explore if clinical occupational therapists were using the tool. The survey was sent to all Gauteng public healthcare institutions that employed occupational therapists involved in adult rehabilitation. Table II above shows the composition, distribution and results of the survey.

\section{Data Gathering Tools and Analysis}

The field notes, reflective journaling and meeting minutes were systematically analysed by the researchers. In keeping with good practice analysis, and in support of action research principles ${ }^{11,42}$, the raw data were manually checked and analysed immediately after gathering, throughout the process. Data were summarised and categorised, and these summaries drove and dictated the next ALAR cycles and research stages.

Care was taken to process all decision making through the VRTT and to avoid power relationships that could jeopardise the emancipatory nature of action research ${ }^{43}$. Data were captured in the form of VRTT meeting minutes, field notes and reflective journaling. The researcher kept her own reflective journal. While participants were using the user manual, they were followed up by a designated mentor who summarised presented feedback at VRTT meetings, where it was captured in meeting minutes.

\section{Credibility, Transferability, Dependability and Conformability}

Confidence in the credibility, transferability, dependability and conformability of the findings were pursued throughout. The collaborative nature of action research ensures built in checks for credibility and conformability consideration. In this study, outsider experts on the subject matter were used as critical friends and insider critical reflection was routinely employed to ensure confidence in the results of the inquiry. Data analysis of the survey results saw two of the authors, working independently of each other, transcribe and thematically analysed the data. They compared their interpretations and confirmed a consensus opinion for use in this paper. Using in- siders as co-researchers and developing the driver screening tool within the context it will be used ensures high dependability value. For the same reason caution should be exercised when considering transferability of the knowledge generated in this study.

\section{Ethical Clearance, Informed Consent and Bias Declaration}

Ethical clearance of the research and informed consent of all participants fell under the larger $\mathrm{PhD}$ study with the ethical clearance number MI30649. There is no bias to declare.

\section{RESULTS AND DISCUSSION}

The observation that driving rehabilitation was the first concern, tabled within the collaborative research group, could be indicative of the urgency of the problem. There was also awareness in the group of a social justice factor due to the lack of accessibility and available of driving rehabilitation for injured and/or disabled drivers who are dependent on public healthcare. In planning to address the practice problem Mtetwa et al's $s^{8}$ call for South African occupational therapists to do research and publish in the field of driving rehabilitation came to light, confirming the VRTT's resolve to approach the problem systematically. Considering the problems praxis the VRTT realised that international driving rehabilitation practices could not be drafted directly into the South African context. In addition they found that as the field was sparsely researched in South Africa there were basic underlying principles missing. Grounding premises were decided on to guide the development of a contextually relevant Driver Screening Tool and are shown in Table III on page 8.

Using these premises, a draft user manual to screen fitness to drive was developed by the PhD candidate who saw it through multiple individual cycles of planning-acting-reflecting-improving. The manual was designed to be easy to read and use by clinical occupational therapists in adult practices at all levels of public healthcare in Gauteng.

Critical reflection at the end of Cycle One showed that two out of 38 workshop attendees used the tool and no feedback was given. The VRTT therefore decided on a new action cycle, demonstrating the democratic validity ${ }^{44}$ of ALAR as an inherent part of the study. Cycle Two saw 16 VRTT members and their 


\begin{tabular}{|l|l|}
\hline Grounding premise one & $\begin{array}{l}\text { Occupational therapists, at all levels of care in public healthcare, have a responsibility to address the question } \\
\text { of their patient's ability to drive a motor vehicle. This is to curb out of pocket expenses, misunderstandings and } \\
\text { non-compliance, which can occur due to referral of patients to specialist units or expert therapists. }\end{array}$ \\
\hline Grounding premise two & $\begin{array}{l}\text { Adhering to HPCSA guidelines, occupational therapists with no additional skills and training in driving } \\
\text { rehabilitation can only screen a patient's ability to drive. } \\
\text { Screening provides an opportunity to counsel and inform patients, their families and employers of their } \\
\text { obligations and available resources. } \\
\text { Screening determines whether assessment is needed, alleviating the demand on driving assessment resources. } \\
\text { Additional training and certification is necessary before an occupational therapist becomes involved in driving } \\
\text { assessment, intervention and accommodation. }\end{array}$ \\
\hline Grounding premise three & $\begin{array}{l}\text { The screening process enables therapists to: } \\
\text { (i) Identify individuals who cannot and should not drive and have no prospect of recovering sufficient function to } \\
\text { do so. These individuals, and their families, can then be assisted to address this loss and the restrictions it places } \\
\text { on their lives; } \\
\text { (ii) Identify individuals who could potentially drive. If the screening indicated no restriction to drive, individuals } \\
\text { should be referred for an assessment. If their ability to drive is associated with improvement of their medical } \\
\text { condition, access to assistive devices, vehicle adaptations, and/or additional skills training, these persons should } \\
\text { be referred accordingly. }\end{array}$ \\
\hline
\end{tabular}

colleagues use the tool in their clinical practices, critically reflect on it and provide this as feedback to enable improvement of the tool. The improvement reported to be of most practical value was the development of a clinical guide that therapists could laminate and use in clinical settings. The clinical guide can be found in Appendix I at the end of this article.

The VRTT agreed to finalise the Screening Fitness to Drive user manual, which was written assuming basic level occupational therapy skills. The user manual consisted of a cover letter, background and general information, legal and ethical considerations, a stepby-step guide, conclusion, recourses, skills training and suggested readings and references. The dissemination of this screening tool and user manual saw a growing interest beyond Gauteng Province.

Three years after the driver-screening tool had been in use in Gauteng public healthcare sector, the VRTT decided to investigate its use. A user survey was developed. The results showed that $41 \%$ of responding facilities used the driver screening tool, but only once or twice a year. Opinion on the usefulness of the tool showed that $91 \%$ of respondents were positive about the tool. They felt it was a good tool to have, relevant to their patient profile, easy to use and understand and they planned to use it in future. The $8 \%$ who included negative feedback indicated that having screened their patients, they had created an awareness of and a hope for driving rehabilitation intervention in their patients. These patients could not access private driving rehabilitation services due to the costs involved and within the Gauteng public healthcare, there were no driving rehabilitation resources to which they could be referred.

\section{LIMITATIONS AND ANTICIPATED FUTURE ALAR CYCLES}

Without incorporating the voice of injured and/or disabled drivers the relevance and sustainability of a driving rehabilitation service or intervention needs to be questioned. All future enquiries by South African occupational therapists need to start with this in mind.

Screening and creating an awareness of driving rehabilitation without having accessible referral sources impacts on the veracity of occupational therapy practice and is an ethical concern. Future research to inform and motivate policy makers to address this void within public healthcare should be seen as a matter of urgency, especially as it demonstrates compliance with the South African Constitution ${ }^{45}$ and $\mathrm{NHI}^{46}$ goals.

The ALAR design used in this research enriched the professional lives of therapists and created a service that was not previously available to patients in public healthcare. It did so incorporating input to the body of knowledge from the inexperienced occupational therapist as well as acknowledged experts in the field. The result was contextually relevant and for this reasons it was suggested as a design for future research and development of the field of driving rehabilitation within public healthcare. Continued ALAR cycles will also be necessary to ensure evolvement of the screening tool to keep up with ever changing legislation, healthcare environments and client and practitioner needs.

With any action research done as insider-outsider collaboration, the justification of knowledge claims and how power and control over the research process were distributed needs, to be a concern $^{44}$. Even though all efforts were made to reduce the negative impact of power relations, it could still have been operative as the insider group consisted predominantly of inexperienced therapists and the outsiders were seen as experienced experts in the field of driving rehabilitation.

\section{CONCLUSIONS}

The use of the ALAR methodology was directly linked to the willingness of the collaborative research group to take on a practice problem they perceived to be complex and daunting. The research resulted in the development of a contextually relevant screening tool and user manual that allows drivers, who use public healthcare in Gauteng, access to the preliminary stage of driving rehabilitation. Clinical occupational therapists in Gauteng public healthcare now have a standard approach to screen their patients' fitness to drive a motor vehicle and ALAR cycles continue to improve and update the service.

Screening Fitness to Drive is a valuable resource as it reduces the pressure on scarce and expensive assessment resources. Used within public healthcare the screening tool has the additional benefit of creating awareness of intervention and rehabilitation that can enable driving independence and all its associated benefits and opportunities. However, there can be no meaningful impact unless it is efficiently linked with driving assessment and other driving rehabilitation services. To achieve this occupational therapist will have to cross the boundaries of private-public healthcare and extend their practices into other sectors, such as transport, labour and legislature.

\section{ACKNOWLEDGEMENTS}

Stakeholders and members of the VRTT: Simon Rabothata, Ashley Magner, Naazneen Ebrahim, Claudette Parkinson, Mashudu Mphohoni, Catherine Couvaras, Buhle Moleofane, Lynn Soulsby, Madidimalo Mogale, Marlene Robus, Mariaan Jacklin, Zakkiya Akhalwaya, Siphosethu Nxumalo, Alta Voster, July Masango

The experts and critical friends who contributed towards the finalisation of the user manual: Caroline Rule, Lee Randall, Tania Buys, Megan Spavins, Janine Schoeman, Derryn Brummer, Megan Townshend, Jane Baker, all members of the Driving Interest Group, 
the Skills Basket and Work-Link.

The 2013 Faculty of Health Sciences Development Grant from the University of the Witwatersrand.

\section{REFERENCES}

I. Sherman FT. Driving: the ultimate IADL. Geriatrics. 2006; 6I (I0): 9-10. http://worldcat.org/issn/0016867X.

2. Motsoaledi A. $84 \%$ of South Africans get 2 nd rate healthcare. News 24. 2013.

3. van Rensburg HCJ. South Africa's protracted struggle for equal distribution and equitable access - still not there. Human Resources for Health. 20 I4; I2(26). https://doi.org/ I0. I |86/ |478-449|-12-26.

4. Stuckler D, Basu S, McKee M. Health care capacity and allocations among South Africa's provinces: infrastructure-inequality traps after the end of apartheid. American Journal of Public Health. 201 I; I0I(I): 165-72. http://doi.org/10.2 I05/AJPH.2009. 184895.

5. Lehohla P. National Household Travel Survey - Gauteng Profile. June 2014, Pretoria: Statistics South Africa; 2015.

6. Golisz K. Occupational Therapy Interventions to Improve Driving Performance in Older Adults: A Systematic Review. American Journal of Occupational Therapy. 2014; 68: 662-9. http://doi.org/10.5014/ajot.2014.01 I 247.

7. Canadian Association of Occupational Therapists (CAOT). CAOT Position Statement Occupational Therapy and Driver Rehabilitation. 3704; 2009.

8. Mtetwa L, Classen S, van Niekerk L. The lived experience of drivers with a spinal cord injury: A qualitative inquiry. South African Journal of Occupational Therapy. 2016; 46(3): 55-62. http://dx.doi.org/10.17159/2310-3833/2016/v46n3al0.

9. van Biljon H, Casteleijn D, du Toit S, Soulsby L. Opinions of Occupational Therapists on the Positioning of Vocational Rehabilitation Services in Gauteng Public Healthcare. South African Journal of Occupational Therapy. 2016; I (I): 45-53. http://dx.doi.org/l0.17/59/23 I0-3833/2016/v46n Ial0.

10. van Biljon $H$, Casteleijn D, du Toit S. Developing a vocational rehabilitation report writing protocol - a collaborative action research process. South African Journal of Occupational Therapy. 20 15; 45(2): I5-2 I. http://dx.doi.org/I0.17|59/23 I0-3833/20I5/V45N2A4.

II. McNiff J. Concise Advice for New and Experienced Action Researchers. Action Research for Professional Development. Dorset: September Books; 2010. .

12. Wiegand DM, Hickman JS, Geller ES. Automobile Safety During Adulthood. New York: Springer US; 2014.

13. Wolfe PL, Lehockey KA. Neuropsychological Assessment of Driving Capacity. Archives of Clinical Neurospsychology. 20 I6; 3 I (6): 517-29.

14. Harkey D, Griffith M, Staplin L, Ross L. Taxonomy and Terms for Stakeholders in Senior Mobility E-C21 I; 2016.

I5. Carr D, Schmader K, Bergman C, Simon TC, Jackson TW, Haviland $S$, et al. A Multidisciplinary Approach in the Evaluation of Demented Drivers Referred to Geriatric Assessment Centers. Journal of the American Geriatrics Society. I991; 39(I I): I I 32-6. https://onlinelibrary.wiley.com/doi/abs/ I0. I I I I/j. I532-54 I5. I99|.tb02882.x.

16. Jerome L, Segal A. Prediction of Driving Accident Risk in Novice Drivers in Ontario: The Development of a Screening Instrument. Dr. Lisa Dorn, editor. London: Routledge; 2017.

17. Vrkljan BH, Myers AM, Blanchard RA, Crizzle AM, Marshall S. Practices Used by Occupational Therapists and Others in Driving Assessment Centers for Determining Fitness-to-Drive: A CaseBased Approach. Physical \& Occupational Therapy In Geriatrics. 2015; 33(2): I63-74.

https://www.tandfonline.com/doi/abs/10.3109/02703181.2015.1016647.

18. Imhoff $S$, Lavallière $M$, Teasdale $N$, Fait $P$. Driving assessment and rehabilitation using a driving simulator in individuals with traumatic brain injury: A scoping review. NeuroRehabilitation, 2016; 39(2): 239-5 I. https://www.ncbi.nlm.nih.gov/pubmed/27372359. http://doi.org/10.3233/NRE-I6/354.

19. Unsworth CA, Bakera A. Driver rehabilitation: A systematic review of the types and effectiveness of interventions used by occupational therapists to improve on-road fitness-to-drive. Accident Analysis and Prevention, 2014; 7I: 106-14. https://www.ncbi.nlm.nih.gov/ pubmed/24906 I64. http://doi.org/10.1016/j.aap.2014.04.017.

20. Di Stefano M, Stuckey R. Ergonomic Considerations for Vehicle
Driver-Cabin Configurations: Optimizing the Fit Between Drivers with a Disability and Motor Vehicles. Söderback I, editor. Cham: Springer; 2015.

2I. Devos H, Akinwuntan AE, Nieuwboer A, Truijen S, Tant M, De Weerdt W. Screening for fitness to drive after stroke. A systematic review and meta-analysis. Neurology. 201 I; 76(8): 747-56. https://doi.org/10.1212/WNL.0b013e31820d6300.

22. Kielhofner G. Conceptual Foundations of Occupational Therapy Practice. Philadelphia: F A Davis Company; 2009. ISBN: 9780803620704.

23. Davis ES, Stav WB, Womack J, Kannenberg K. Driving and community mobility. American Journal of Occupational Therapy. 2016; 70(64SI I2). Epub 10.5014/ajot.2010.64SII2. http://search.proquest.com/docview/2080983 I 38 .

24. Unsworth CA, Harries P, Davies M. Using Social Judgment Theory method to examine how experienced occupational therapy driver assessors use information to make fitness-to-drive recommendations. British Journal of Occupational Therapy. 20I5; 78(2): I09-20. https://doi.org/I0. I I 77/03080226/4562396.

25. Bruce C, Unsworth CA, Tay R, Dillon MP. Development and validation of the Occupational Therapy Risk Propensity Test (OT-RiPT) for drivers with disability. Scandinavian Journal of Occupational Therapy. 2015; 22(2): 147-52. https://doi.org/10.3109/1 1038128.2014.992952.

26. Dickerson AE, Meuel DB, Ridenour CD, Cooper K. Assessment Tools Predicting Fitness to Drive in Older Adults: A Systematic Review. American Journal of Occupational Therapy. 2014; 68: 670-80. https://doi.org/10.5014/ajot.2014.011833.

27. Rule C. Positioning and set-up of the vehicle for drivers with spinal cord injury. FOCUS - Official Newsletter of OTASA. 2014; 3: 40-3.

28. Ebrahim N. Disability and Driving. An Intersectorial Workshop. South African Psychiatry. 2018; 15:47-49. Epub http://www.southafricanpsychiatry.co.za.

29. Republic of South Africa. Amendment of the National Road Traffic Regulations. National Road Traffic Act; 1996 (ACT NO. 93 OF 1996); 2014.

30. Özerdem A, Bowd R. Participatory Research Methodologies. Development and Post-Disaster/Conflict Reconstruction. Ist ed. London: Routledge; 2016. https://doi.org/10.4324/978I3I55995I9.

31. Townsend A. Action Research: The Challenges Of Changing And Researching Practice. UK: Open University Press; 2013 isbn $=0335244432$.

32. Stringer ET. Action Research. California: SAGE; 2014 isbn $=|48332073|$.

33. Brook C. Action Learning in Healthcare. Dilworth RL, Bohyk Y, editors. Hampshire: Palgrave Macmillan; 2010.

34. Reason P, Bradbury H. Handbook of Action Research. London: SAGE Publications Ltd; 2007. isbn = I4I 2920302.

35. Marsick V, O' Neil J. The Many Faces of Action Learning. Management Learning. 2010; 30(2): 159-76. https://doi.org/10.1 I 77/1350507699302004.

36. Zuber-Skerritt O. Action Learning and Action Research. Songlines through Interviews. Rotterdam, Netherlands: Sense Publishers; 2009.

37. Dick B. Entry and Contracting. Action research and evaluation online. Australia: www.aral.com.au/areol; 2013.

38. Maseko L, Erasmus A, Di Rago T, Hooper J, O' Reilly J. Factors that influence choice of placement for community service among occupational therapists in South Africa. South African Journal of Occupational Therapy, 2014; 44(I): 36-40. http://dx.doi.org/I0.17/59/2310=3833/2016/v46n3al.

39. Costa A, Kallick B. Through the lens of a critical friend. Educational Leadership. 1993; 5 I(2): 49-5I.

40. van Biljon HM. Transforming the Vocational Rehabilitation Services of Occupational Therapists in Gauteng Public Healthcare through Action Learning Action Research. Parktown, Johannesburg: University of the Witwatersrand; 2016.

4I. van Biljon HM, Rabothata S. Screening ability to drive in occupational therapy. 35th National Congress of the Occupational Therapy Association of South Africa; Birchwood Hotel \& Conference Centre Johannesburg; 2016.

42. Creswell J. Qualitative inquiry and research design (2nd ed). CA Sage: Thousand Oaks; 2007. https://psycnet.apa.org/re- 
cord/2006-13099-000

43. du Toit S, Wilkinson A. Research and Reflection: Potential Impact on the Professional Development of Undergraduate Occupational Therapy Students. Springer Science + Business Media; 20 I 0; 23(Systematic Practical Action Research): 387-404. Epub 5 February 2010. http://doi.org/|0.1007/s I | 213-010-9165-5.

44. Herr K, Anderson GL. The Action Research Dissertation: A Guide for Students and Faculty. United States of America: SAGE; 2005. http://dx.doi.org// 0.4I35/978|452226644.

45. Republic of South Africa. The Constitution of the Republic of South Africa, Act 108 of 1996; 1996.
46. Republic of South Africa. National Health Insurance (NHI) White Paper. Pretoria; Government Printers; 2017.

Corresponding Author

$H$ van Biljon

HesterMvanBiljon@gmail.com

\section{Appendix I \\ Clinical Guide to Screen fitness to Drive}

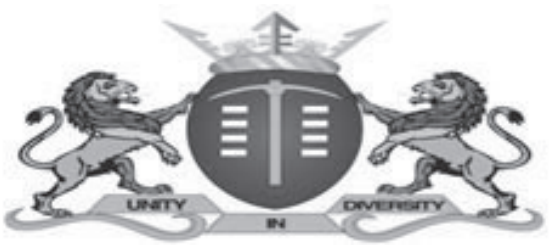

GAUTENG PROVINCE

HEALTH

REPUBLIC OF SOUTH AFRICA

Familiarise yourself with the user manual Occupational Therapy Protocol for Screening Ability to Drive before using this guide.

\section{Step I: Prepare for the screening}

You need: Green Card, basic graduate level occupational therapy (OT) physical and psycho-social knowledge, assessment skills and clinical reasoning, number plate, stop watch, Jamar Hand Dynamometer or Oxford Muscle Strength Scale, MoCA or other baseline cognitive test, activities of physical and psycho-social skills comparable to driving functions, standard chair and table, 20 meter walking area.

\section{Before you start the screening go through the following check list:}

I. Have I read and understood Legal and Ethical Considerations for Occupational Therapists when Screening Ability to Drive in the protocol?

2. Do the patient and I, know and understand why we are doing the screening?

3. Do we know and agree on what will happen to the findings of the screening?

4. Do I know what normal and abnormal and safe and unsafe driving is?

5. Do understand the medical condition, injury or disability of the patient?

6. Do I know the effect that the pathology, medical intervention and medication could have on ability to drive?

7. Do I have professional empathy with the patient I am going to screen?

8. Do I have adequate objectivity to make a professional decision?

If you answered No to any question, comply with the suggestion of the question or refer to another OT. If you are able to answer Yes to all the questions proceed to step 2 .

\section{Step 2: The initial interview}

Use the interview guide and note insight/planning/judgment, vision, epilepsy, uncontrolled diabetes.

I. History of illness/disability, medication and treatment.

2. Personal background.

3. Driving history and needs.

After the initial interview you should be able to answer the following questions:

I. Have we been able to communicate effectively to do this screening?

If you answer No, find means to correct each problem before continuing with the screening.

2. Does my patient have uncontrolled epilepsy?

3. Does my patient have sudden attacks of disabling giddiness or fainting?

4. Does my patient have any mental illness that requires him/her to be detained, supervised, controlled in terms of the Mental Health Act, 1973?

5. Does my patient have any condition causing muscular incoordination?

6. Does my patient have uncontrolled diabetes mellitus?

7. Does my patient have any disease/defect which is likely to render him/her incapable of effectively driving and controlling a motor vehicle?

If you answered Yes to any of questions 2 to 7 your patient cannot drive. Address this.

If you answered No to questions 2 to 7 you can continue the screening. 


\section{Step 3: Do a physical screening as required for driving}

I. Muscle strength, muscle tone and range of motion.

2. Sensation: Note any sensation problems that could affect driving.

No matter what the disability do visual screening and consider the question:

Does my patient have defective vision in accordance with prescribed standards?

If Yes stop the screening and refer to relevant specialists. If No continue with the screening.

3. Reaction speed

4. Hand function

5. Balance and co-ordination as relates to driving

6. Endurance as it relates to driving

7. Mobility

\section{Step 4: Do a psycho-social screening as required for driving}

I. Attention, concentration, memory, planning, decision-making, problem-solving, reasoning, judgement, multi-tasking, social skills, self-control and insight.

2. Place your patient on a level of creative ability, volition and action.

3. Consider the question: Are they a 'road-rage' risk?

Step 5: Come to a decision on whether your patient cannot or could drive a motor vehicle.

Start by asking yourself the following questions:

Do I have enough information to make a decision? Yes

Has my screening been fair and realistic?

No

If your answer is No, get the missing information or refer to another occupational therapist.

If you can answer Yes continue with the decision making.

Consider the questions:

\begin{tabular}{|c|c|c|c|}
\hline I. Can the patient recognize and assess the seriousness of traffic dangers? & Yes & No & Unsure \\
\hline $\begin{array}{l}\text { 2. Would my patient have sufficient command of their vehicle not to create a dangerous situation and to } \\
\text { react appropriately should such a situation occur? }\end{array}$ & Yes & No & Unsure \\
\hline 3. Can my patient comply with road traffic regulations? & Yes & No & Unsure \\
\hline 4. Can my patient detect major technical vehicles faults and have them remedied in an appropriate fashion? & Yes & No & Unsure \\
\hline $\begin{array}{l}\text { 5. Can my patient take account of factors affecting driving behaviour (fatigue) so as to retain full use of } \\
\text { faculties needed to drive safely? }\end{array}$ & Yes & No & Unsure \\
\hline 6. Can my patient help ensure the safety of all road users by showing due respect for others? & Yes & No & Unsure \\
\hline 7. Can my patient have effective and reliable control of a vehicle? & Yes & No & Unsure \\
\hline $\begin{array}{l}\text { 8. Does my patient have the necessary sensory function, cognitive function and musculoskeletal function to } \\
\text { respond to the road, traffic and other external cues? }\end{array}$ & Yes & No & Unsure \\
\hline 9. Does my patient have knowledge of and willingness to follow the rules of the road? & Yes & No & Unsure \\
\hline
\end{tabular}

If you are Unsure of any of the above, remedy the situation.

If you answer No to any of the above questions your patient cannot drive.

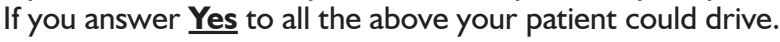

You need to make one of two decisions:

One: 'This patient cannot drive.'

Two: 'This patient could drive.'

Check that there is adequate evidence to support your decision.

\section{Step 6: Conclude with a closure interview}

The patient should understand: That the screening is over, your future role in their lives, what will happen with the information and who will have access to the information. Working with the patient, form a practical, easy to follow chronological step-by-step plan-of-action addressing driving in their lives.

\section{Step 7: You now need to report your screening results}

